\title{
Pengenalan Wajah Bebas Ekspresi Menggunakan Metode Nearest Feature Line dengan Representasi Ciri dalam Ruang Eigen
}

\author{
Is Mardianto ${ }^{1}$ \\ ${ }^{1}$ Program Studi Teknik Informatika, Fakultas Teknologi Industri, Universitas Trisakti, Jakarta, Indonesia \\ mardianto@trisakti.ac.id
}

Diterima 17 April 2020

Disetujui 17 Juni 2020

\begin{abstract}
Facial recognition with different expressions is one part of the pattern recognition problem which is quite complex when compared to pattern recognition on a normal profile. The expression-free face recognition method using the Nearest Feature Line (NFL) technique works by finding the closest projection distance between feature vectors, assuming that the closer the projection distance of a feature vector (face) to another feature vector (face), the more similar the properties will be physical feature vector (face) which are close together. The NFL distance calculation is performed on the eigen dimensional space with the aim that the calculated feature vector (face) dimension has a much smaller dimension in order to increase the level of recognition accuracy and speed up computational time. The test results obtained indicate the NFL method provides a fairly good level of recognition accuracy in the average value of $76.7 \%$ with the advantage of low computational time needed when compared with other intelligent methods such as artificial neural network systems.
\end{abstract}

Index Terms-Eigen Value, Expression, Face Recognition, Nearest Feature Line, Principal Component Analysis

\section{PENDAHULUAN}

Saat ini perkembangan teknologi pengukuran dan analisa statistik yang berkaitan dengan data biologis berkembang dengan pesat. Penyebabnya karena ciri biologis manusia memberi informasi yang unik berkaitan dengan identifikasi seseorang. Dalam ranah ilmu komputer, teknologi biometrik merujuk kepada teknologi pengukuran dan analisis karakteristik bagian tubuh manusia suara, mata, wajah dan sidik jari.

Dalam hal membaca sifat-sifat bagian tubuh manusia seperti wajah dibutuhkan peralatan penyimpan dan penganalisis pola. Saat "user" mencoba mengakses suatu sistem, maka sistem akan membandingkan data biometrik yang tersimpan dengan data biometrik yang akan mencoba masuk. Algoritme biometrik yang baik akan mampu memutuskan dengan benar apakah "user" yang sedang mencoba mengakses suatu sistem diperkenankan atau tidak memperoleh akses kedalam sistem tersebut. Pada kasus ini, obyek yang sama dengan perbedaan asesoris wajah harus dapat dikenali sebagai satu obyek yang sama. Untuk memenuhi kebutuhan tersebut dikembangkanlah sistem pengenalan wajah bebas ekspresi dengan menggunakan metode Nearest Feature Line.

\section{LANDASAN TEORI}

\section{A. Teorema Proyeksi}

Metode Nearest Feature Line (NFL) [1] bekerja dengan memanfaatkan teorema proyeksi yaitu "jarak sebuah titik kesebuah bidang adalah jarak tegak lurus dari titik ke bidang tersebut" seperti terlihat pada Gambar 1.

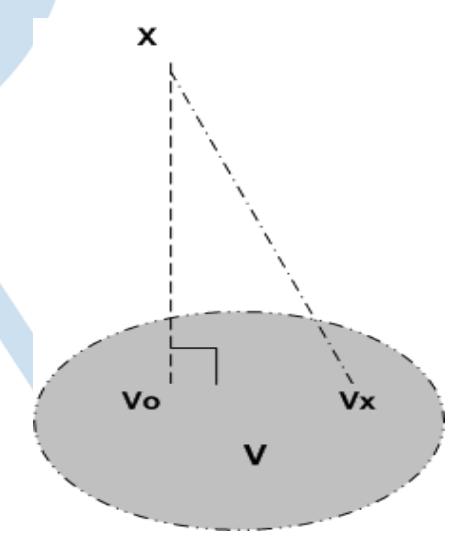

Gambar 1. Proyeksi titik pada sebuah bidang

Dari teorema proyeksi [2] dapat diturunkan sebuah teknik NFL untuk mencari jarak terpendek antara sebuah vektor ciri dengan himpunan vektor ciri lainnya [3].

Dari ilustrasi Gambar 2, dapat diturunkan solusi dari pencarian jarak citra uji T3 terhadap garis ciri yang menghubungkan citra acuan T1 dan T2.

Berdasarkan prinsip interpolasi linear bila diberikan 2 buah titik dalam ruang (T1 dan T2) maka dapat dibentuk sebuah garis lurus yang melewati kedua buah titik tersebut yang memenuhi persamaan 1 . 


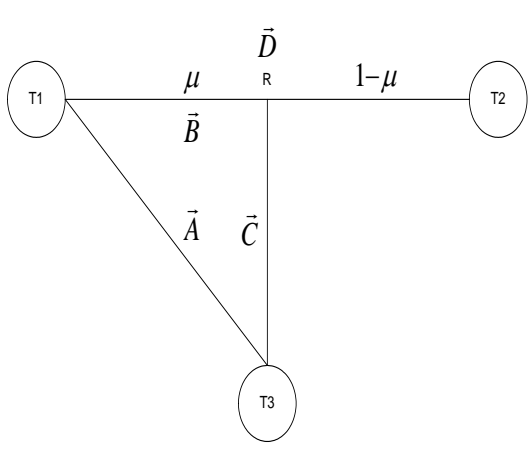

Gambar 2. Penurunan rumus teknik NFL

$$
\mathbf{R}=(1-\mu) \mathbf{T} 1+\mu \mathbf{T} 2=\mathbf{T} 1+(\mathbf{T} 2-\mathbf{T} 1) \mu
$$

sehingga $\mu=\frac{(\mathbf{R}-\mathbf{T} 1)}{(\mathbf{T} 2-\mathbf{T} 1)}$

dengan

$\mathrm{A}=\mathrm{T} 3-\mathrm{T} 1, \mathrm{~B}=\mathrm{R}-\mathrm{T} 1, \mathrm{C}=\mathrm{T} 3-\mathrm{R}, \mathrm{D}=\mathrm{T} 2-\mathrm{T} 1, \mathrm{~A}=\mathrm{B}+\mathrm{C}$

maka $\mu \mathbf{D}=\mathbf{B}$,

$$
\mu(\mathbf{D} \bullet \mathbf{D})=\mathbf{B} \bullet \mathbf{D}=(\mathbf{A}-\mathbf{C}) \bullet \mathbf{D}=\mathbf{A} \bullet \mathbf{D}-\mathbf{C} \bullet \mathbf{D}
$$

karena jarak terpendek yang dapat dibentuk sebuah titik terhadap sebuah garis adalah hasil perpotongan antara garis yang ditarik dari titik terhadap garis acuan yang membentuk sudut sebesar $90^{\circ}$ maka sudut yang dibentuk antara vektor C dengan D adalah $90^{\circ}$, sehingga persamaan 2 menjadi:

$$
\mu(\mathbf{D} \bullet \mathbf{D})=\mathbf{A} \bullet \mathbf{D}
$$

sehingga didapatkan solusi:

$$
\mu=\frac{(\mathbf{A} \bullet \mathbf{D})}{(\mathbf{D} \cdot \mathbf{D})}=\frac{(\mathrm{T} 3-\mathrm{T} 1) \cdot(\mathrm{T} 2-\mathrm{T} 1)}{(\mathbf{T} 2-\mathrm{T} 1) \cdot(\mathbf{T} 2-\mathrm{T} 1)}
$$

sedangkan untuk menghitung jarak terdekat antara T3 dengan $\mathbf{R}$ :

$$
\begin{aligned}
& \operatorname{Jarak}[\mathbf{T 3},(\mathbf{T} 2-\mathbf{T 1})]=\mid \mathbf{T 3}-\mathbf{R} \| \\
& \| \mathbf{T 3}-\left[\mathbf{T 1}+(\mathbf{T} 2-\mathbf{T} 1)\left[\frac{(\mathbf{T 3}-\mathbf{T 1}) \cdot(\mathbf{T} 2-\mathbf{T} 1)}{(\mathbf{T} 2-\mathbf{T} 1) \cdot(\mathbf{T} 2-\mathbf{T} 1)}\right]\right] \mid
\end{aligned}
$$

Solusi persamaan (4) digunakan secara praktis untuk menghitung jarak terpendek kemiripan antara sebuah citra dengan citra lainnya dengan memandang sebuah citra sebagai sebuah vektor ciri.

\section{B. Eigen Value dan Eigen Vector}

Pemahaman tentang konsep "eigen value" dan "eigen vector" dijelaskan dalam bentuk persoalan fisis [4]. Terdapat matriks $M$ yang menggambarkan bentuk deformasi membran akibat mendapat perlakuan fisik yakni ditarik, dirotasi dan ditekan terhadap titik asal. Maka setelah deformasi, titik awal pada bidang membran $(\mathrm{x}, \mathrm{y})$ berubah lokasi menjadi $(\mathrm{X}, \mathrm{Y})$.

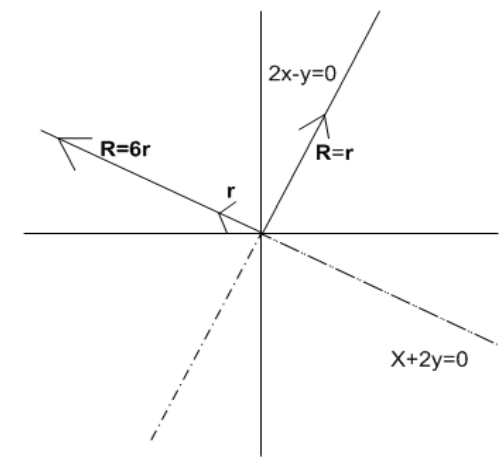

Gambar 3. Interpretasi fisis eigen value dan eigen vector

Interpretasi dari bentuk tersebut seperti terlihat pada Gambar 3 adalah "eigen value" yang terbentuk dari matriks transformasi memberi informasi tentang besar nilai deformasi bidang membran yang terjadi, sedangkan "eigen vector" matriks transformasi memberi informasi tentang arah pergerakan yang terjadi akibat perubahan deformasi bidang membran tersebut [4].

\section{TEKNIK PENGENALAN}

\section{A. Representasi Citra Wajah}

Wajah sebagai ukuran biometrik merupakan kerangka fisis yang dapat direpresentasikan sebagai sekumpulan informasi dalam hal ini berupa nilai intensitas citra wajah. Representasi dari $\mathrm{n}$ buah vektor/citra dapat dinyatakan sebagai sehimpunan $\mathrm{n}$ buah sampel berdimensi d berupa $\mathbf{x}_{1}, \mathbf{x}_{2}, \ldots, \mathbf{x}_{n}$.

Permasalahan bisa timbul jika representasi citra wajah tersebut cukup besar untuk diolah dalam sistem komputasi, untuk mengatasi masalah tersebut salah satunya adalah dengan menggunakan metode Principal Component Analysis (PCA). Metode PCA bekerja dengan prinsip bahwa jumlah kuadrat jarak antara $\mathbf{x}_{0}$ (vektor representasi) dengan vektor yang akan direpresentasikan $\mathbf{x}_{k}$ sekecil mungkin [5].

\section{B. Teknik PCA}

Teknik PCA dimulai ketika Harold Hotelling [5] mengajukan teknik baru yang bertujuan untuk mengurangi jumlah dimensi sebuah ruang yang biasanya direpresentasikan oleh variabel statistik $\mathrm{x}_{1}$, $\mathrm{x}_{2}, \ldots, \mathrm{x}_{n}$, dimana variabel-variabel tersebut biasanya saling berkorelasi satu dengan yang lain. Akibat konsekuensi sifat tersebut, lalu muncul pertanyaan apakah ada himpunan variabel baru yang sifatnya relatif sama dengan variabel yang diwakili sebelumnya, dan diharapkan himpunan variabel baru tersebut memiliki jumlah dimensi (variabel) yang lebih sedikit dari dimensi sebelumnya. Dikemudian 
hari transformasi dimensi ini dikenal dengan nama Transformasi Hotelling atau Transformasi Karhunen Loeve dan tekniknya dikenal dengan nama Principal Component Analysis (PCA) yang "basis" kerjanya berdasarkan prinsip statistika dari citra [6].

Teknik Principal Component Analysis (PCA) terdiri atas beberapa langkah yaitu :

1. Jika diasumsikan terdapat himpunan $\mathrm{p}$ buah citra pelatihan yang direpresentasikan kedalam matriks $\mathrm{X}=\left[\mathrm{X}_{1}, \mathrm{X}_{2}, \ldots \mathrm{X}_{\mathrm{p}}\right]$ dengan dimensi tiap citra adalah $\mathrm{q}$ (baris $\mathrm{x}$ kolom), maka dapat dibentuk matriks data pelatihan Y dengan orientasi vektor kolom sebagai berikut:

$$
Y=\left[\begin{array}{cccc}
x_{11} & x_{12} & \ldots & x_{1 q} \\
x_{21} & x_{22} & \ldots & x_{2 q} \\
\ldots & \ldots & \ldots & \ldots \\
x_{p 1} & x_{p 2} & \ldots & x_{p q}
\end{array}\right]
$$

dengan $\mathbf{X}_{\mathbf{i j}}$ menunjukkan nilai intensitas dari piksel citra pelatihan ke-i variabel (dimensi) ke-j.

2. Matriks Y kemudian di-normalisasi menjadi:

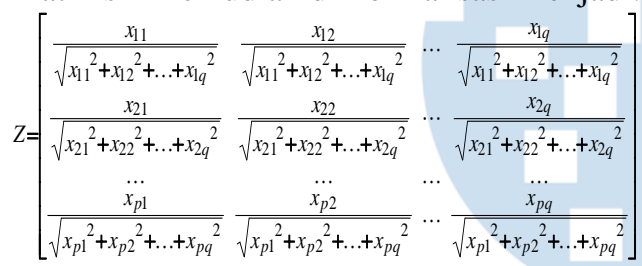

3. Hitung rata-rata vektor citra $\mu_{j}=\frac{1}{p} \sum_{i=1}^{p} Z_{p j}$. Lalu bentuk matriks rata-rata $\mu=\left[\begin{array}{llll}\mu_{1} & \mu_{2} & \ldots & \mu_{q}\end{array}\right]$.

4. Hitung selisih vektor citra dengan rata-rata vektor citra $A=Z-\mu$.

5. Dari matriks A langkah ke-4, hitung matriks total scatter berupa matriks kovarian yang bersifat real dan simetrik $S=A A^{T}$ (berordo q $\times$ q).

6. Tentukan "eigen vector" $\mathrm{V}$ dan "eigen value" D dari matriks S pada langkah ke-6, dan urutkan eigen vector secara "ascending order".

7. Tentukan dimensi ruang ciri yang akan digunakan berdasarkan aturan: $m=\min q\left\{\frac{\sum_{i=1}^{q} D_{i}}{\sum_{i=1}^{p} D_{i}}>\theta\right\}$
8. Reduksi "vector eigen" $\mathrm{V}$ menjadi "vector eigen" sesuai dengan nilai $m$ yang akan dikenal dengan istilah "eigenfaces".

9. Transformasi vektor citra menjadi vektor ciri $A V^{\prime T}$.

\section{HASIL DAN PEMBAHASAN}

Berbeda dengan penelitian sebelumnya yang menggunakan metode Nearest Feature Line untuk menguji klasifikasi pola pada "half face" [7], penelitian ini menggunakan metode Nearest Feature Line untuk menguji tingkat akurasi pengenalan wajah dengan ekspresi yang berbeda-beda, dengan pose wajah dibatasi diambil dari tampak depan dan kualitas foto dibatasi pada dimensi citra $35 \times 42$ pixel. Data sampel yang digunakan sebanyak 44 buah yang terbagi kedalam 4 kelompok orang, dengan berbagai macam ekspresi dan hambatan visual diantaranya: berkacamata, berbayang pada satu sisi, normal, tersenyum, merengut, memejamkan mata, tertawa dan mengedipkan satu mata. Komputasi dijalankan pada bermacam data wajah yang telah direduksi dimensinya menggunakan metode Principal Component Analysis dengan tujuan untuk mencari ciri-ciri terpenting dari wajah. Dengan harapan dapat mengurangi beban lamanya waktu komputasi akibat besarnya dimensi ciri wajah yang diolah.

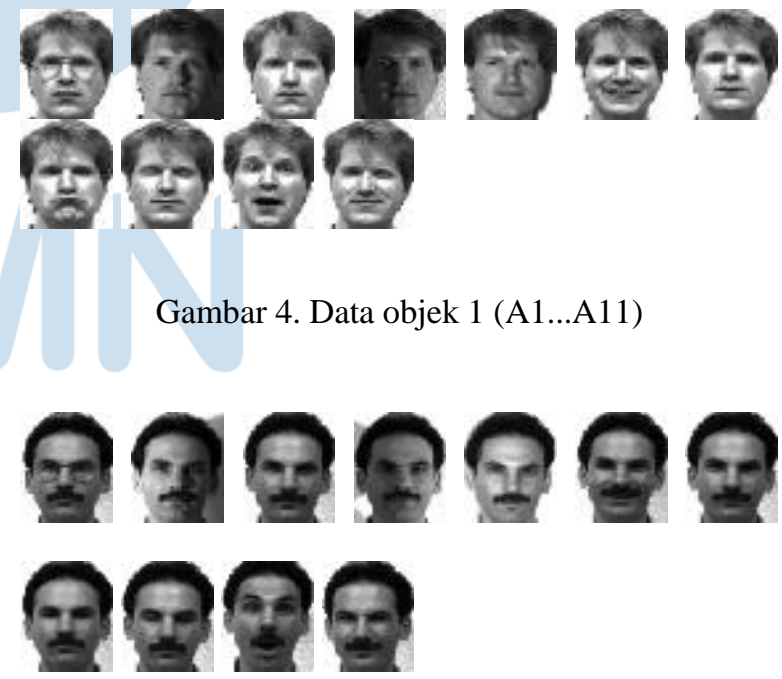

Gambar 5. Data objek 2 (B1...B11) 


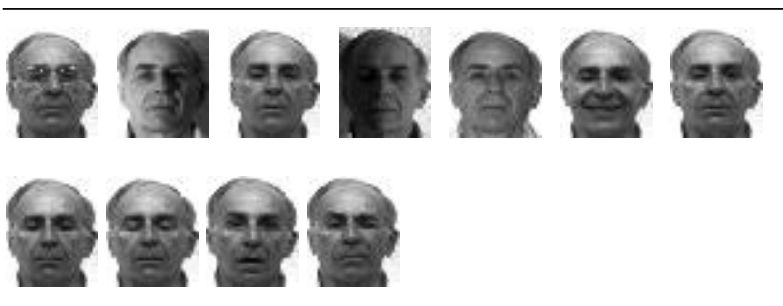

Gambar 6. Data objek 1 (C1...C11)

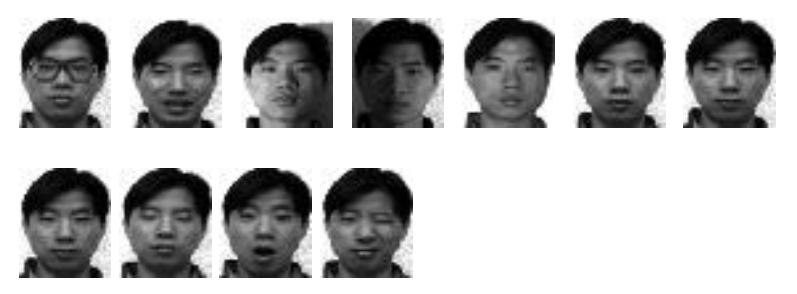

Gambar 7. Data objek 1 (D1...D11)

\section{A. Teknik Klasifikasi Menggunakan Metode NFL}

Teknik klasifikasi dilakukan dengan terlebih dulu membentuk garis ciri Eigen pada setiap vektor (gambar) acuan yang terdapat pada basis data seperti yang ditunjukkan pada Gambar 4, 5, 6 dan 7. Jika dimisalkan menggunakan masing-masing 3 vektor (gambar) acuan untuk setiap sampel/kelas A, B, C dan $\mathrm{D}$, maka akan terdapat 3 garis ciri Eigen untuk setiap sampel/kelas uji A, B, C dan D. Selanjutnya vector (gambar) uji yang akan diklasifikasi akan dihitung jarak NFL-nya terhadap setiap garis ciri Eigen yang terbentuk sebelumnya yakni 12 garis ciri Eigen seperti ditunjukkan pada Gambar 8. Penentuan klasifikasi suatu vector (gambar) uji masuk kedalam kelas A, B, C atau D ditentukan berdasarkan jarak terpendek yang diperolehnya, dalam kasus Gambar 8, Gambar uji A6 terklasifikasi sebagai kelompok/kelas wajah A dikarenakan jarak NFL-nya paling pendek terbentuk dengan garis ciri A1 dengan A2 dan hasil ini dianggap benar karena vektor(gambar) ciri A6 memang berada pada kelas kelompok wajah A.

Penelitian ini menguji 7 jenis percobaan seperti yang ditunjukkan pada tabel 3, dimana hasil optimal didapatkan pada kasus 6 buah vektor acuan dengan 5 buah vektor uji untuk setiap masing-masing kelas wajah A, B, C dan D.

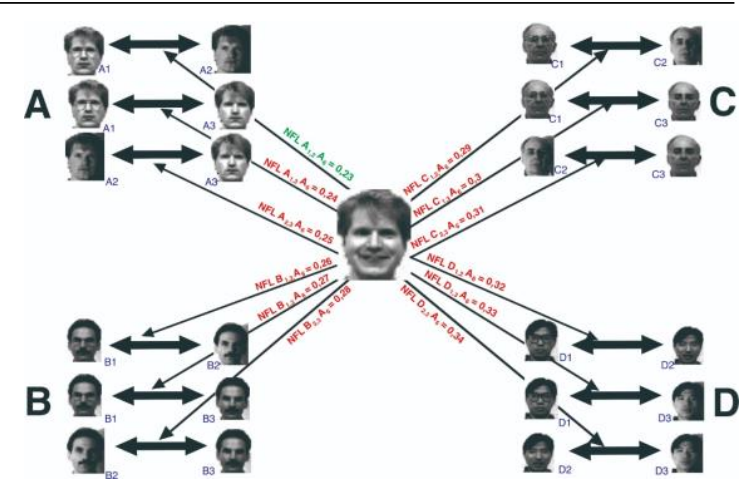

Gambar 8. Teknik klasifikasi NFL

B. Sampel Implementasi Model 5 Vektor Acuan, 6 Vektor Uji

Tabel 1. Vektor acuan (5) dan vektor uji (6)

\begin{tabular}{|c|c|}
\hline $\begin{array}{c}\text { Vektor Acuan } \\
\text { (File) }\end{array}$ & $\begin{array}{c}\text { Vektor Uji } \\
\text { (File) }\end{array}$ \\
\hline SA1 ...SA5 & SA6...SA11 \\
SB1 ...SB5 & SB6...SB11 \\
SC1 ...SC5 & SC6...SC11 \\
SD1 ...SD5 & SD6...SD11 \\
\hline
\end{tabular}

Hasil perhitungan jarak terdekat dan ketepatan klasifikasi dari sampel; 5 vektor acuan dan 6 vektor uji diilustrasikan pada Tabel 2.

Tabel 2. Hasil pengujian jarak sampel Tabel 1

\begin{tabular}{|c|c|c|}
\hline File Uji & Kategori & Jarak \\
\hline SAISA006.txt & termasuk SA 0 4 & 0.234973 \\
\hline SAISA007.txt & termasuk SC 1 4 & 0.159983 \\
\hline SAISA008.txt & termasuk SA 2 4 & 0.414572 \\
\hline SAISA009.txt & termasuk SA 0 4 & 0.343121 \\
\hline SAISA010.txt & termasuk SA 0 4 & 0.129782 \\
\hline SAISA011.txt & termasuk SA 0 4 & 0.224511 \\
\hline SBISB006.txt & termasuk SB 0 2 & 0.196233 \\
\hline SBISB007.txt & termasuk SB 0 2 & 0.309947 \\
\hline SBISB008.txt & termasuk SB 0 2 & 0.267249 \\
\hline SBISB009.txt & termasuk SB 1 2 & 0.231585 \\
\hline SBISB010.txt & termasuk SD 0 4 & 0.479127 \\
\hline SBISB011.txt & termasuk SB 0 2 & 0.20002 \\
\hline SCISC006.txt & termasuk SC 1 2 & 0.319528 \\
\hline SCISC007.txt & termasuk SC 2 3 & 0.122509 \\
\hline SCISC008.txt & termasuk SC 1 2 & 0.343282 \\
\hline SCISC009.txt & termasuk SC 1 2 & 0.366861 \\
\hline SCISC010.txt & termasuk SC 2 3 & 0.161312 \\
\hline SCISC011.txt & termasuk SC 2 3 & 0.134812 \\
\hline SDISD006.txt & termasuk SA 0 3 & 0.571568 \\
\hline SDISD007.txt & termasuk SA 0 3 & 0.609441 \\
\hline
\end{tabular}


ISSN 2085-4552

\begin{tabular}{|l|l|l|} 
SDISD008.txt & termasuk SA 0 3 & 0.609441 \\
\hline SDISD009.txt & termasuk SD 0 4 & 0.491857 \\
\hline SDISD010.txt & termasuk SA 1 3 & 0.555666 \\
\hline SDISD011.txt & termasuk SA 1 3 & 0.572898 \\
\hline
\end{tabular}

Ket: warna merah menandakan salah klasifikasi

Tingkat akurasi: 70,83\%

\section{Hasil Eksperimen Lengkap}

Dari Tabel 3, Terlihat metode NFL menunjukkan hubungan tingkat keakuratan dengan jumlah vektor acuan yang digunakan, dimana semakin banyak jumlah vektor acuan meningkatkan akurasi pengenalan. Hal ini disebabkan semakin banyak vektor acuan maka jumlah garis vektor uji dengan vektor acuan juga semakin banyak, yang pada akhirnya berkontribusi pada pilihan garis vektor terpendek yang bisa dipilih.

Tabel 3. Tingkat akurasi pengenalan wajah (bebas ekspresi) dengan metode NFL

\begin{tabular}{|c|c|c|c|c|c|c|c|}
\hline $\begin{array}{c}\text { Jumlah } \\
\text { Vektor }\end{array}$ & 3 & 4 & 5 & 6 & 7 & 8 & 9 \\
Acuan & & & & & & & \\
\hline Jumlah \\
Vektor
\end{tabular}

\section{SIMPULAN}

Kesimpulan yang dapat ditarik dari pengenalan wajah dengan ekspresi yang berbeda-beda menggunakan metoda NFL adalah:

a. Semakin banyak vektor acuan, semakin tinggi tingkat akurasi pengenalan wajah.

b. Secara rata rata tingkat akurasi metode NFL mendekati tingkat akurasi metode Back Propagation [8] pada penelitian lain [3] dimana secara rata-rata diatas $85 \%$.

c. Untuk model dan karakter penelitian yang sama, waktu komputasi metode NFL jauh lebih singkat dibandingkan metode Back Propagation, dimana untuk pelatihan Back Propagation dengan 50.000 epoch membutuhkan waktu rata-rata 446 detik, sedangkan metode NFL proses perhitungan jarak hingga klasifikasi membutuhkan waktu rata-rata 15 detik, hal ini dikarenakan metode NFL tidak mengalami proses pembelajaran berulang seperti halnya Back Propagation [8], melainkan cukup menghitung jarak terpendek [1] antara vector eigen acuan dengan vektor uji. Sehingga jika ukuran waktu menjadi pertimbangan maka metode NFL sangat layak dijadikan metode pengenalan pola yang handal.

Kedepannya penelitian ini dapat dikembangkan dengan meningkatkan tingkat akurasi pengenalan, dengan jalan memperbaiki metode pencarian proyeksi jarak terdekat dengan model matematika yang baru atau hasil modifikasi metode NFL.

\section{UCAPAN TERIMA KASIH}

Penulis mengucapkan banyak terimakasih kepada Fakultas Teknologi Industri Universitas Trisakti atas bantuan moril dan materil hingga selesainya penelitian yang penulis lakukan.

\section{DAFTAR PUSTAKA}

[1] L. Zhao, W. Qi, S. Z. Li, S.-Q. Yang, and H. J. Zhang, "Keyframe extraction and shot retrieval using nearest feature line (NFL)," in Proceedings of the 2000 ACM workshops on Multimedia - MULTIMEDIA '00, 2000, pp. 217-220, doi: $10.1145 / 357744.357942$.

[2] W. C. Moon, Todd K., Stirling, Mathematical Methods and Algorithms for Signal Processing. Prentice-Hall, Inc, 2000.

[3] I. Mardianto, "Sistem Pengenalan Wajah 3Dimensi Dengan Automatisasi Penentuan Konstanta Bobot Sudut Pandang Berdasar Pada Penerapan Metode Proyeksi Jarak Terdekat dan Representasi Ciri Pada Ruang Eigen,” 2004.

[4] Mary L. Boas, Mathematical Methods in the Physical Sciences, 3rd ed. Wiley, 2005.

[5] R. O. Duda, P. E. Hart, and D. G. Stork, Pattern classification 2001.

[6] Yu-Jin ZHANG, Image Engineering. Processing, Analysis and Understanding. Cengage Learning Asia Pte Ltd, 2009.

[7] Q. Feng, L. Yan, T. S. Pan, and J. S. Pan, "Nearest feature line and extended nearest feature line with half face," in Advances in Intelligent Systems and Computing, 2014, doi: 10.1007/978-3-319-01796-9_8.

[8] L. Fausett, Fundamentals of Neural Network, Architectures Algorithms and Applications. Prentice Hall, 1994. 